\title{
Evaluating the effect of structural dimensions on the successful implementation of strategies in Payam-e-noor University of Iran
}

\author{
Hamidreza Shahhosseini ${ }^{{ }^{*}}$, Vahidreza Mirabi ${ }^{\mathrm{b}}$ and Ali Jamshidi ${ }^{\mathrm{c}}$
}

${ }^{a}$ M.A. of Executive Management, Electeronic Branch, Islamic Azad University, Tehran, Iran

${ }^{b}$ Faculty member, Central Branch, Islamic Azad University, Tehran, Iran

${ }^{c}$ Faculty member, Lavasanat Branch, Payam-e-noor University, Tehran, Iran

\section{CHRON I CLE ABSTRACT}

\section{Article history:}

Received January 14, 2013

Received in revised format

30 May 2013

Accepted 6 June 2013

Available online

June 82013

Keywords:

Strategic management

Strategy

Strategy implementation

Structural dimension

Strategy effectiveness

\begin{abstract}
This study aims to assess the relationship between structural dimensions of organization including centralization, complexity and formalization on one side and strategy effectiveness on the other side. Structural dimensions are determined based on Robbins theory, and each of them is considered as independent variables of research. Strategy effectiveness, which includes achieving strategic goals or successful implementation of strategies are the dependent variable of the research, based on Noble's strategy implementation model. One primary thesis and three secondary these are defined. This is a descriptive research of two variable correlation. The target population includes 600 senior managers of Payam-e-noor university around the country, including staff administrative managers, province and unit headmasters, of Iran at the time of data collection. Simple random sampling is used, with sample size of 120 .

Library resources are used for theoretical foundation data collection and note-taking. Questionnaires are used to collect data and evaluate research theses. Inferential Statistics and Pearson correlation coefficient are used to analyze the research theses. The first two theses are confirmed, at $95 \%$ and $99 \%$ respectively, but the third thesis is rejected based on the collected data. Therefore, based on this study, complexity and formalization have respectively inverse and direct effect on strategy effectiveness, but centralization does not affect strategy effectiveness in Payam-e-noor University.
\end{abstract}

\section{Introduction}

Strategic management rules and concepts help managers and employees better understand activities and priorities of firms. It can also empower an organization to be creative and innovative, and prevents it from passive attitude in shaping its future (David, 2001). Today's environmental circumstances make most goals, structure and behavior of institutions inefficient over the long term. That is why many firms require being more innovative and requiring a managerial structure capable 
of open and outward strategies, as a primary objective of strategy is to adapt an institution to the environment, to the extent that institutional resources and capacities allow. An institution with no strategy is like a ship with no compass and many institutional failures are rooted in lack of strategy, inappropriate strategies, or incorrect implementation of strategies (Amirkabiri, 2010). If strategies are established, but never implemented, this will also be an aimless action to an institution (David, 2001). Organizational structure is one of the essential factors of strategy implementation and it determines the decision-making process, reporting process, and hierarchy of authority. According to Robbins (1990), structure, as one part of organization, incorporates three dimensions of complexity, formalization, and centralization and while it is commonly acceptable framework, it is not universally accepted. This study examines the effect of structural dimension of organization on the effectiveness of strategies including acquiring strategic goals, or successful implementation of strategies.

\section{Literature review}

\subsection{Problem statement}

Many institutional failures are black for the lack of strategy, inappropriate strategies, or incorrect implementation of strategies. Strategy elevates the quality of organizational decisions but any strategy without implementation does not convey a meaningful concept (Amirkabiri, 2010). Successful establishment of strategies does not guarantee successful implementation (David, 2001). Several factors influence the implementation of strategies and when a strategy is applied within an organization, it is expected to build a strong relationship between structure and strategy. The chosen strategy determines which objectives will be realized, and which tasks will be executed to reach these goals, and how the work should be broken down. In other words, structure needs to follow the strategy, logically (Amirkabiri, 2010). However, there are major concerns on how to determine the structure. The authority of managers to change strategy can be less than how it seems; and the structure might determine the strategy, while the opposite does not always hold. Therefore, it seems that the impact of strategy in forming the structure is bigger in the early stages of structure formation (Robbins, 1990). However, it is not dubious that structure influences the strategy (David, 2001).

In Iran, only few firms have considered strategic management, and recently few of them have started to compile strategic guidelines. However, in most cases, the issue has stayed at the compilation of guidelines, and the strategies have never been executed.

According to Okumus (2001), less than $10 \%$ of compiled strategies are executed, successfully. The ability to execute the strategy is much more important than the quality of strategy itself (Kaplan \& Norton, 2000). Therefore, it is essential to detect the important factors in implementation of strategies. There are some studies on determining effect of strategy compilation on structure but the effect of structural dimensions on implementation of strategies has not discussed, yet. On the other hand, most of the researchers have considered structure as one of the effective factors in strategy implementation, along with others, and some of them prioritized the effective factors and compared with the impact of structure. It is clear that in these studies the effect of structural dimensions are not evaluated independent of other factors, but they are relatively prioritized.

We can conclude that, on the other hand, the importance of the subject for Payam-e-noor University, with more than a million students in 2011 , covering more than $30 \%$ of total students in the country, and more than 500 academic institutions around the country, is very high. It is essential to study the structural dimensions of Payam-e-noor University and their effect on strategy implementation. In 2009, Payam-e-noor University compiled a draft of university's strategic guidelines. While this draft is not published officially, but the content, from vision to strategies (future plans of the university) can be found on the official portal of Payam-e-noor University (www.pnu.ac.ir). Therefore, we can say that Payam-e-noor University considers the importance of strategic management and strategy implementation, as an important step in this process, has a particular place for the managers of this university. Therefore, the question is that how the structural dimensions of this university can affect 
the effectiveness of the chosen strategies and help the university in reaching its strategic goals. This study aims to answer this question.

Based on what is said until now, a research gap in this field is clear. Researchers in Iran should study the effects of structural dimensions on the successful strategy implementation in Iranian organizations, including universities in depth.

\subsection{Theoretical Foundations of the Study}

This study has one primary, and three secondary questions. The primary question is on the effects of structural dimensions of organization on the effectiveness of strategies in Payam-e-noor University. The secondary questions are the effect of each of these dimensions including complexity, formalization as well as centralization on the effectiveness of strategies. In these questions, independent parameters including complexity, formalization, and centralization are considered the structural dimensions of organization, based on Robbins definition. The scientific goal of this research is to determine the effect of each of these dimensions on the effectiveness of strategies and prioritizing them based on their effect. Noble's model, theoretical foundations of which is discussed later in this paper, is used to assess the effectiveness of strategies. Clearly, research theses are also defined in accordance with the research questions. The researchers presumed that all of the structural dimensions affect the effectiveness of strategy. According to what was said, conceptual model of the research is shown below:

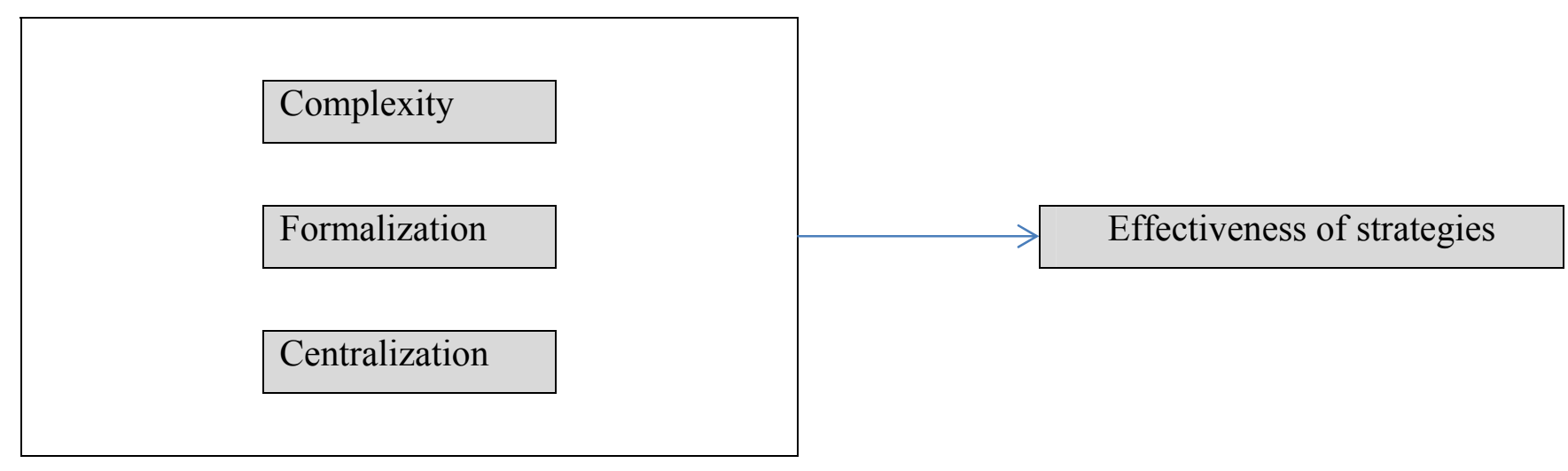

Fig. 1. Conceptual Model of the Research (Robbins, 1990)

\subsection{Research Hypothesis}

The Main Hypothesis: organizational structure affects the effectiveness of strategies in Payam-enoor University.

\section{Sub- Hypothesis}

$\mathbf{H}_{\mathbf{1}}$ : Complexity affects the effectiveness of strategies in Payam-e-noor University.

$\mathbf{H}_{2}$ : formalization affects the effectiveness of strategies in Payam-e-noor University.

$\mathbf{H}_{3}$ : centralization affects the effectiveness of strategies in Payam-e-noor University.

\subsection{Essence of Strategy Implementation}

Strategy implementation can be stated as decision-making on the compatibility of strategy and structure, financing, operational strategies, incentive systems, and monitoring the effectiveness of strategies (Byars, 1991). According to Jauch and Glueck (1988), strategy implementation is a process including a set of compatible and coordinated decisions and actions performed to assign resources, organize, commission the key managers, regulate the policies, and establish an executive system to 
reinforce, control, and evaluate the strategy. Thompson and Strickland (1998) defined strategy implementation as a process linking the strategy compilation to a set of actions ensuring that vision, mission, strategy, and strategic goals of organization are successfully achieved as planned. According to Hunger and Wheelen (2008), strategy implementation is a set of activities and decisions essential for implementation of a strategic plan.

Process of strategy implementation involves all the management tasks, including planning, organization, inspiration, leadership, guidance, coordination, communications, innovation, and control (Higgins, 1983). Successful compilation of strategy does not guarantee successful implementation of strategies. It is always difficult to perform the job (strategy implementation) than to claim what should be accomplished (strategy compilation). While strategy implementation has an incommensurable and unclear link with strategy compilation, these two are different (David, 2001). The most important problems in the strategic management process are not about strategy compilation, but strategy implementation (Flood et al., 2000). In addition, the main cause of the high rate of failure in organizations in changing environments is the weak implementation of new strategies (Jooste \& Fourie, 2009). Only 10 percent of compiled strategies are accomplished, practically. If implementation of one strategy fails, compilers blame the implementation team. In other words, any failure in strategic implementation is definitely a failure in compilation. However, the real problem is hidden in this separation of compilation and implementation, and division of thought (strategy compilation) and action (strategy implementation) (Mintzberg et al., 1998). Compilation and implementation work as two allies, and not rivals, to guide the strategies. Successful implementation of a correctly compiled strategy can contribute to the organization performance in reaching long-term visions, missions, and plans, and lead to organizational success (Crittenden \& Crittenden, 2008). In strategy implementation, management encounters different issues such as identification of annual objectives, compilation of policies, assignment of resources, etc. If organization requires to step in to a completely various path to perform a strategy, managerial changes are highly essential (David, 2001).

\subsection{Effective Factors for Strategy Implementation}

According to Hoskisson et al. (2008) strategic leadership can be defined as "the ability to anticipate, envision, maintain flexibility and empower others to create strategic change as necessary". Whaterman et al. (1980) introduced one of the major frameworks for explanation the effective factors for strategy implementation. His team, based on a consulting research project, concluded that effective implementation of strategy depends on the relation between 7 factors of strategy, structure, systems, management style, staff, skills, and mutual values (Rezaeian, 2003).

\subsection{Noble's Model of Strategy Implementation}

Noble (1999) emphasized the critical requirement for accurate and comprehensive conceptual frameworks on strategy implementation although such a model still does not exist. Some of the researches have introduced frameworks for strategy implementation, and discussed the effective items on the elements of strategy. Yang et al. (2009) emphasized that the studies in the second category could gather several factors in one framework or model. Thus, not only grouping of implementation variables, but also organizing them along the lines of a network of cause and effect or time relations have to be studied. Based on executive perspectives and surveying middle managers, a generic model of the main steps for strategy implementation is derived. This model focuses on practical issues and dynamics. The model has the following 4 main stages:

1- Pre-implementation efforts

2- Organizing the implementation effort,

3- Managing the implementation process

4- maximizing the performance of counteractive functioning 
Understanding the challenges and problems in each stage, helps most top managers improve the effectiveness of strategy implementation process (Noble, 1999). As mentioned earlier, Noble's strategy implementation framework is organized in 4 stages. There are five managerial levers to implement these stages, which include goals, organizational structure, leadership, communications and incentives. Based on Noble's theory, management changes these factors during the implementation stages (even though each one of them is important in all the stages). Attention to these factors, in combination with each main stage, creates a useful approach to improve strategy implementation (Noble, 1999). This framework is shown Table 1 and the framework used in this study is based on Noble's model.

\section{Table 1}

Managerial Levers by Implementation Stages Based on Noble's model (Noble, 1999)

\begin{tabular}{|c|c|c|c|c|}
\hline \multirow[b]{2}{*}{ LEVERS } & \multicolumn{4}{|c|}{ STAGES } \\
\hline & Pre- Implementation & $\begin{array}{l}\text { Organizing } \\
\text { Implementation Effort }\end{array}$ & $\begin{array}{l}\text { Managing } \\
\text { Implementation } \\
\text { Process }\end{array}$ & $\begin{array}{l}\text { Maximizing Cross- } \\
\text { functional Performance }\end{array}$ \\
\hline Goals & $\begin{array}{l}\text { Ensure that all } \\
\text { managers are aware } \\
\text { of the strategic goals } \\
\text { of } \\
\text { the firm }\end{array}$ & $\begin{array}{l}\text { Introduce goals of the } \\
\text { strategy being implemented, } \\
\text { incl. } \\
\text { fit within firm's broader } \\
\text { strategic vision }\end{array}$ & $\begin{array}{l}\text { Maintain the } \\
\text { flexibility to adapt } \\
\text { goals based on } \\
\text { environmental } \\
\text { changes }\end{array}$ & $\begin{array}{l}\text { Develop and focus on } \\
\text { common goals to } \\
\text { encourage cross-functional } \\
\text { cohesiveness }\end{array}$ \\
\hline $\begin{array}{l}\text { Organizational } \\
\text { structure }\end{array}$ & $\begin{array}{l}\text { Ensure that } \\
\text { functional areas } \\
\text { have the slack } \\
\text { resources needed } \\
\text { to be able to } \\
\text { contribute to an } \\
\text { implementation } \\
\text { effort }\end{array}$ & $\begin{array}{l}\text { Establish a formal } \\
\text { implementation unit and } \\
\text { ensure its visibility } \\
\text { throughout the firm }\end{array}$ & $\begin{array}{l}\text { Ensure equal } \\
\text { representation by } \\
\text { all affected functional } \\
\text { areas }\end{array}$ & $\begin{array}{l}\text { Temporarily suspend } \\
\text { key implementation } \\
\text { team members } \\
\text { normal responsibilities to } \\
\text { allow them to focus } \\
\text { on the implementation } \\
\text { effort }\end{array}$ \\
\hline Leadership & $\begin{array}{l}\text { Develop employees' } \\
\text { knowledge and } \\
\text { appreciation of } \\
\text { multiple functional } \\
\text { areas }\end{array}$ & $\begin{array}{l}\text { Establish a "champion" } \\
\text { who has both official } \\
\text { cross-functional authority } \\
\text { and general respect in the } \\
\text { firm }\end{array}$ & $\begin{array}{l}\text { Ensure that leaders } \\
\text { show equal attention } \\
\text { to } \\
\text { all functional-level } \\
\text { concerns }\end{array}$ & $\begin{array}{l}\text { Balance visible and } \\
\text { charismatic leadership } \\
\text { with a maintenance of } \\
\text { autonomy for functional- } \\
\text { level implementation } \\
\text { efforts }\end{array}$ \\
\hline Communications & $\begin{array}{l}\text { Maintain regular } \\
\text { cross-functional } \\
\text { communications } \\
\text { to foster } \\
\text { understanding } \\
\text { and appreciation }\end{array}$ & $\begin{array}{l}\text { Discuss and resolve } \\
\text { implementation details } \\
\text { early in the process }\end{array}$ & $\begin{array}{l}\text { Update } \\
\text { implementation team } \\
\text { frequently } \\
\text { on progress and } \\
\text { changes in objectives }\end{array}$ & $\begin{array}{l}\text { Communicate } \\
\text { implementation progress } \\
\text { across the } \\
\text { entire organization to } \\
\text { foster buy-in }\end{array}$ \\
\hline Incentives & $\begin{array}{l}\text { Reward the } \\
\text { development of } \\
\text { cross-functional } \\
\text { skills }\end{array}$ & $\begin{array}{l}\text { Develop time and } \\
\text { performance-based } \\
\text { incentives for } \\
\text { implementation } \\
\text { team while lessening } \\
\text { traditional functional } \\
\text { incentives }\end{array}$ & $\begin{array}{l}\text { Adjust incentives } \\
\text { as strategy and } \\
\text { environmental } \\
\text { conditions change } \\
\text { during } \\
\text { implementation }\end{array}$ & $\begin{array}{l}\text { Establish visible and } \\
\text { consistent cross-functional } \\
\text { rewards for successful } \\
\text { implementation efforts }\end{array}$ \\
\hline
\end{tabular}

\subsection{Structure and Strategy}

Structure of a firm clarifies the tasks and responsibilities, and builds a behavioral links among them. Organizational structure, at the same time, is the skeleton that organization's regenerative power depends on (Amirkabiri 2010). Any strategy is executed within a firm. Thus, there is a strong relationship between structure and strategy in institutions (Amirkabiri, 2010). Organization's top managers should, before executing strategic plans make sure that organization is organized for it (Hunger \&Wheelen, 2008). To study the link between structure and strategy, dimensions and types of structure are first examined, and then the link between these two is discussed. 


\subsubsection{Structural Dimensions of Organization According to Robbins}

According to Robbins (1990), organizational structure defines how the tasks are assigned, who is responsible to report necessary assignments, and what the formal coordination mechanisms and organizational interactive patterns to follow are. Structure has three elements of complexity, formalization and centralization. While it is common to accept these three as the three main dimensions of organizational structure, it is not universally accepted.

Complexity: this is associated with the differentiation level in the organization. Complexity also expresses the expertise levels, professional activities, and duration of professional education of staff.

Horizontal differentiation: this is related to differentiation level among organizational units, based on the position of members, the nature of their tasks, education level and professional education.

Vertical differentiation: This one is also associated with the depth/height of the organizational structure. With increased hierarchy in the organization, the vertical differentiation and complexity are increased. More levels between top management and operational management of the organization is a potential factor to alter the communications, which in turn makes the coordination among staff management and monitoring the operational activities for top management more difficult.

Spatial Differentiation: This item is related to the spatial distribution of units, resources, and human resources. An organization can perform its activities with similar horizontal differentiation and organizational hierarchy in several places. Increased number of places increases the complexity of an organization.

Formalization: it means the level or extent to which the organizational posts are standardized. If a job is highly formalized, the individual in charge of it has the least freedom in how and when he performs the tasks. Staff, in these environments, is expected to use specific inputs with specific methods to lead to anticipated results. Therefore, in highly formalized organizations, specific work descriptions, too many rules and regulations, and clear procedures on the work process exist.

Centralization: Power aggregation in one point specifies centralization, and lack of aggregated power demonstrates decentralization. Centralization is associated with the distribution of decision making authority, not the spatial differentiation of the organization. When decision makings are handed over to the lower hierarchical levels, organization is decentralized. When operational tier staff can decide, but only along the lines of planned organizational policies, this also shows a considerable centralization level (Robbins, 1990).

The centralization concept means the decision making process. If all the important decisions are made by the top management, the system is called fully centralized; but if decision making authority is handed over to operational levels, to create decision making opportunities for them, system is called decentralized (Rezaeian, 2003).

The link between centralization, complexity and formalization: Evidence implies an inverse relationship between centralization and complexity (Alison, 1971; Robbins, 1990). Decentralization is associated with high levels of complexity. For example, the increased number of professional experts means an increase in expertise to make decision. Therefore, when we investigate organizational structure, we have to find high levels of complexity in decentralized organizations (Robbins, 1990).

The relationship between centralization and formalization is vague, as much as the relationship between complexity and centralization is clear and perspicuous. Evidences have indicated inconsistent results. The first study did not confirm a strong relationship between centralization and formalization (Mintzberg, 1979; Robbins, 1990). The next study indicated a strong, but negative, relationship between these two elements of organizational structure, which specifies with increased decentralization, organizational formalization increases (Simon, 1976; Robbins, 1990).

Too much formalization can be linked to centralized or decentralized structure. Organizations with unskilled staff are expected to build numerous rules and regulations to guide them (Robbins, 1990).

\subsubsection{The Relation between Structure and Strategy}

These objectives show how the work breakdown must be split. In other words, strategy is the foundation for inter-organizational distinctions, and structure follows the strategy. There are two primary reasons on why changes in organizational strategies force changes in organizational structure: first, structure is a primary factor determining how long term objectives and policies are built. Second, structure determines how resources are allocated (David, 2001). 
The changes in strategies cause changes in organizational structure. Structure should be designed to facilitate strategy implementation. Without strategy or organizational mission, it is not possible to plan a successful structure. While organizational are growing, they link and merge several major strategies, which increase the structural complexity. When strategies are subject to change, existing organizational structure loses its effectiveness. Structural changes might facilitate the activities of strategy implementation. However, we cannot expect structural changes to lead to good or weak strategies, transform weak managers to suitable managers, or make unqualified products sell. There is no doubt that structure influences strategies. Compiled strategies should be practical and effective, thus, if new strategies require many changes in the structure, it is not an attractive enough option. However, the most important issue is to make changes in the organizational structure and how, to better execute the strategy (David, 2001).

\subsubsection{Traditional Theory of Strategy-Structure, Chandler's Study}

Changes in strategy change the structure in time, and strategies change again after that and the sequence is demonstrated in Fig. 2 (David, 2001).

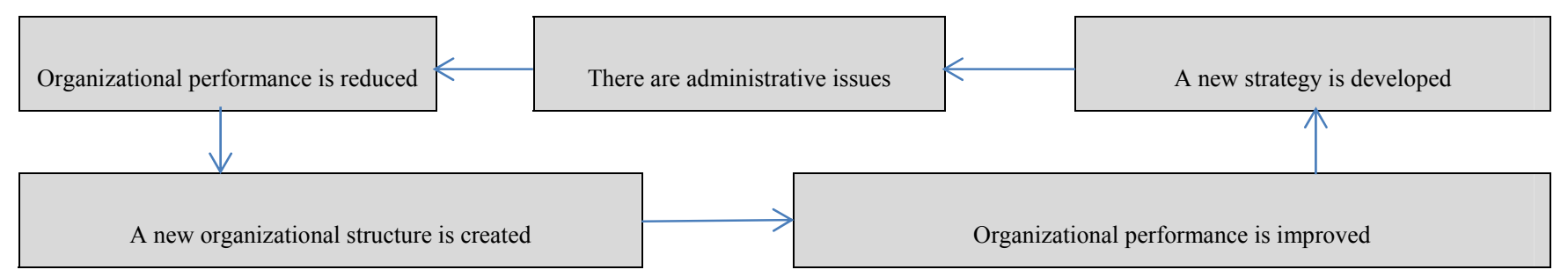

Fig. 2. The relationship between structure and strategy based on the study by Chandler (David, 2001)

\subsubsection{Contemporary Theory of Strategy and Structure, Miles and Snow Study}

Miles et al. (1978) made a development on strategy and structure by developing four kinds of strategic organizations, based on the level of organizational changes in markets or products as follows,

Defender organizations: These organizations look for stabilization, with a limited production of specific products for a small portion of the market. They concentrate on market penetration and propose improving their products for continuous grow. The resulting organization has high horizontal differentiation, centralized control, and formalized hierarchy to communicate.

Prospector organizations: These are considered as the opposite end of defender organizations. Success of prospector organizations relies on producing new products, and maintaining organizational capacity to evaluate a wide range of situations, processes, and environmental events. In these organizations, innovation might be more essential than profitability. As flexibility is important for them, prospector firms aim for a flexible structure with multiple technologies and little monotonousness and mechanization.

Analyzer organizations: These organizations attempt to figure out which of the two mentioned strategies, prospector or defender, is more suitable to invest. Their strategy is to go towards new products or markets with proven futuristic stability and persistence including perpetuity, substance, strength. Analyzer organizations look for both flexibility and stability. They generate a structure with combined components from both strategies.

Reactor organizations: Reactor firms follow a limited strategy and the name describes the unstable and in continuous patterns observed if one of the three mentioned strategies is applied, improperly. Reactor organizations normally act weaker, do not react to the environment, and do not look for equipping themselves with a specific strategy for future. 


\section{Table 2}

The relationship between structure and strategy based on the study by Miles and Snow (Robbins, 1990)

\begin{tabular}{|c|c|c|c|}
\hline Strategy & Goals & Environment & Structural features \\
\hline Defender organizations & Stability and Efficiency & Stable & $\begin{array}{l}\text { Strict control, High division of labor, High } \\
\text { Formalization }\end{array}$ \\
\hline Analyzer organizations & Stability and flexibility & Variable & $\begin{array}{l}\text { Modified centralized control (Strict control over current } \\
\text { operations and Little control over the new activities) }\end{array}$ \\
\hline Prospector organizations & flexibility & Dynamic & $\begin{array}{l}\text { Flexible structure, Low division of labor, Low } \\
\text { Formalization }\end{array}$ \\
\hline
\end{tabular}

The theory of Miles and Snow is summarized in Table 2 as follows where we can we can find the objectives of each strategy, the environment for each strategy, structural mechanisms where management implement to realize objectives. The key element of Miles' theory is the environmental uncertainty assessment of organization's management.

According to Miles et al. (1978), when management forecasts higher uncertainty and environmental changes, strategy moves to the right side of the continuum, accordingly. Therefore, organizational structure should be redesigned to become flexible and adaptable. Under defender strategy, management does not recognize environmental changes and uncertainty. Under this condition, successful structure must be designed to optimize the efficiency. This efficiency can be obtained based on high level of work breakdown, operational standardization, high level of formalization, and centralized decision making.

All managers following analyzer strategy better understand environmental uncertainty and changes, but they need to wait for the competitors' trustable and stable response to accept it and quickly react to the environment. Finally, prospector strategy needs the highest level of structural flexibility. Structure must be highly adaptive to follow the environmental uncertainty, which means that it should have low complexity and formalization, with decentralized decision making (Miles et al., 1978).

\subsubsection{Limitations of Strategy Determinant Power}

No one claims that strategy is unable to decide the structure. It appears that the role of strategy in shaping the structure is stronger in the early phases of organization lifetime. When employees are hired, equipment are also purchased. Policies, processes and regulations are setup and all these resist to changes. The other limitation is associated with delay or time gap (Robbins, 1990).

\section{Research method}

In this study, descriptive method with two variable correlations is used. In this method, the goal is to find the correlation between changes in two variables (Sarmad et al., 2006). Library resources are used for theoretical foundation data collection and note-taking. Questionnaires are used to collect data and evaluate research theses.

\subsection{Target Population}

Target population of this research is the managers of Payam-e-noor University, including administrative managers, state and unit managers, summing up to 600 individuals. Simple random sampling is used. This means that every one of the target individuals have equal chances of being chosen (Sekaran and Bougie, 1984).

\subsection{Statistical Sample:}

To determine the appropriate number of samples, there are several formulas commonly used, depending on the type and objectives of the research. Using the " $\mathrm{d}$ " level and desired reliability, the number, $\mathrm{n}$, is calculated as (Sarmad et al., 2006):

$\mathrm{n}=\frac{\mathrm{Z}^{2} \mathrm{pq}}{\mathrm{d}^{2}}$ 
where $\mathrm{p}=$ (prevalence from previous studies), and $\mathrm{q}=1-\mathrm{p}$. if $\mathrm{p}$ is not known, it can be set as 0.5 , in which case the variance would be the highest, 0.25 (Sarmad et al., 2006). For 95\% reliability, when the first error $(\alpha)$ equals to $0.05, \mathrm{Z}$ equals 1.96 and $\mathrm{d}$, the highest acceptable error in calculating the average effect of structural dimensions on effectiveness of strategies, is set as 0.08 . Using the above formula, the sample size, $n$, is calculated as 150 . If:

$\frac{\mathrm{n}}{\mathrm{N}} \leq 0.05$

The sample size from the above formula is the final number of samples. But as here this proportion $(\mathrm{n}=150)$ to $(\mathrm{N}=600)$ is 0.35 , which is higher than 0.05 , sample population is balanced using the formula below, using 150 as n。(Sarmad et al., 2006):

$\mathrm{n}^{\prime}=\frac{\mathrm{n}_{\circ}}{1+\frac{\mathrm{n}_{\circ}}{\mathrm{N}}}$

Using Eq. (3), sample population is calculated as 120. Questionnaires were delivered to the sample population, chosen from Payam-e-noor University units' managers around the country and the central administration of this University, using email and postal services, or in person. Eventually, 117 filled questionnaires were delivered to the researchers.

\subsection{Measurement Tool}

Library resources are used for theoretical foundation data collection and note-taking. Questionnaires are used to collect data and evaluate research theses. Two different questionnaires are used in this study. At first several questions are given to assess demographics of respondents, including sex, age, military service history, organizational post, latest academic recognition, and management background. This information helps in analyzing research results.

\subsubsection{Questionnaire 1}

This questionnaire is about organizational structure. The questionnaire has 16 questions, standardized by Robbins. The first three questions assess the complexity of the organization. The answers help the researcher to logically estimate the complexity of an organization. The higher the total score of these questions are, the higher will be the complexity. The next 5 questions determine the formalization level, and the answers can estimate the formalization level in a unit or organization. The main elements of formalization are clear boundaries for work descriptions and regulations, supervision levels, the freedom given to lower levels staff and managers, standardization level of job, existing regulations, and how much they are implemented in practice. The last 8 questions are about centralization level in the organization (Robbins, 1990).

It should be noted that from the total 23 questions on Robbins standard questionnaire, 20 were chosen at first, and then after the primary test and calculating Cronbach's Alpha, 4 questions were omitted to increase the reliability.

\subsubsection{Questionnaire 2}

This questionnaire is aimed at evaluating the effectiveness of strategies. A researcher-built questionnaire is used in this case, designed to be appropriate for this study's environment. This questionnaire has 26 statements. Likert scales are used to measure these statements. Likert scale is a common scale to measure viewpoints. Respondent shows his agreement with each of the statements in a scale, usually from 1 to 5 (or 7). This answer is than evaluated (rank-based). The sum of the scores gives the final score in this scale (Sarmad et al., 2006). This scale can be in particular covers the following opinions: completely disagree, disagree, no opinion, agree, and completely agree (Sekaran and Bougie, 1984). 
The first 10 statements of the second questionnaire are from the most important strategies mentioned in the draft of Payam-e-noor University strategic guidelines, all of them in line or in conformance to the main goals and tasks, and future plans of this university published on the official portal of the university. The next 16 statements are organized around the 4 main stages of Noble's model of strategy, which are (1) Pre-implementation efforts, (2) Organizing the implementation effort, (3) Managing the implementation process, and (4) maximizing the performance of counteractive functioning.

\subsubsection{Questionnaire validity and reliability}

To assess questionnaires' validity, content validity method and to assess their reliability, Cronbach's Alpha method is used. If alpha is higher than 0.7, the tool has a high reliability. To calculate the Cronbach's alpha, 20 questionnaires were randomly distributed among some of the sample population, and SPSS(20) was used to calculate the Cronbach's Alpha for the filled questionnaires. The results for questionnaire 1, questionnaire 2, and all of the questionnaires are as listed in Table 3.

Table 3

Cronbach's Alpha for the questionnaires, using SPSS

\begin{tabular}{lcc}
\hline Questionnaire & Cronbach's Alpha & No. of items \\
\hline All the questionnaires & 0.945 & 42 \\
Questionnaire 1 & 0.801 & 16 \\
Questionnaire 2 & 0.948 & 26 \\
\hline
\end{tabular}

\section{Results}

In this study, statistical methods and techniques including descriptive statistics, abundance tables, distribution percentage, graphs, Pearson correlation coefficient using a SPSS software tool.

\subsection{Questionnaire 1 results:}

The average score for complexity is 11 out of 15 . This means that according to the respondents, the structural complexity of the university is relatively high. The average score for formalization is 16.8 out of 25. This means that according to the respondents, the structural formalization of the university is higher than average. The average score for centralization is 25.1 out of 40 . This means that according to the respondents, the decision making centralization of the university is higher than average.

\subsection{Questionnaire 2 results:}

Distribution percentage of respondents against the effectiveness levels for strategy is assessed. 10 respondents $(8.5 \%)$ think the effectiveness level is low; 74 respondents $(63.2 \%)$ evaluate the effectiveness level as medium; and 33 respondents $(28.2 \%)$ evaluate the effectiveness level as high. The average score is 84.6 out of 130 , and this means that according to the respondents the effectiveness of strategies is higher than medium.

\subsection{Results of One Sample Kolmogorov-Smirnov Test}

In interpreting the results, if the significance is more than 0.05 , then the observed distribution is the theoretical distribution and no difference between these two exists. In other words, variable distribution is closer to normal distribution. Here, the significance of results $(0.811)$ is higher than 0.05 , therefore, we can say that the distribution of responses follows the normal distribution, and observed distribution is similar to theoretical distribution. Thus, parametric tests should be used for evaluating the research thesis. The results are shown in Table 4.

\section{Table 4}

Results of one sample Kolmogorov-Smirnov test

\begin{tabular}{llll}
\hline Average & Standard deviation & Kolmogorov-Smirnov & Significance level \\
\hline 140.83 & 20.93 & 0.638 & 0.811 \\
\hline
\end{tabular}




\subsection{Results of H1 Test:}

H1: Complexity affects the effectiveness of strategies in Payam-e-noor University.

The results in Table 5 show that complexity influences the effectiveness of Payam-e-noor university strategies. The correlation coefficient for this variable is -0.184 with the significance level of 0.047 , which expresses a significant, inverse and weak relation between these two variables.. Therefore, this Hypothesis is proved to at least $95 \%$. In other words, complexity influences the effectiveness of Payam-e-noor university strategies, in a way that if one increases, the other one decreases, and the opposite.

\section{Table 5}

Pearson Correlation Coefficient between Complexity level and Effectiveness of Strategies

\begin{tabular}{cccccc}
\hline Variable & abundance & average & $\begin{array}{c}\text { Standard } \\
\text { deviation }\end{array}$ & $\begin{array}{c}\text { Pearson correlation } \\
\text { coefficient }\end{array}$ & sig \\
\hline Complexity & 117 & 11.01 & 2.486 & & \\
Effectiveness of strategies & 117 & 84.63 & 17.817 & -0.184 & 0.047 \\
\hline
\end{tabular}

\subsection{Results of H2 Test:}

H2: Formalization affects the effectiveness of strategies in Payam-e-noor University.

The results in Table 6 show that Formalization level influences the effectiveness of Payam-e-noor university strategies. The correlation coefficient for this variable is 0.427 with the significance level of 0.000 , which expresses a significant and direct relation between these two variables. Therefore, this Hypothesis is proved to at least $99 \%$. In other words, formalization influences the effectiveness of Payam-e-noor university strategies, in a way that if one increases, the other one also increases, and the opposite.

Table 6

Pearson Correlation Coefficient between formalization level and Effectiveness of Strategies

\begin{tabular}{cccccc}
\hline Variable & abundance & average & $\begin{array}{c}\text { Standard } \\
\text { deviation }\end{array}$ & $\begin{array}{c}\text { Pearson correlation } \\
\text { coefficient }\end{array}$ & sig \\
\hline Effectiveness of strategies & 117 & 84.63 & 17.817 & & \\
Formalization & 117 & 16.79 & 3.459 & 0.427 & 0 \\
\hline
\end{tabular}

\subsection{Results of H3 Test:}

H3: Centralization affects the effectiveness of strategies in Payam-e-noor University.

The results in Table 7 show that there is no significant relation between centralization level and the effectiveness of Payam-e-noor university strategies. The correlation coefficient for this variable is 0.096 with the significance level of 0.305 . Therefore, this Hypothesis is rejected to at least $95 \%$. In other words, centralization does not influence the effectiveness of Payam-e-noor university strategies.

Table 7

Pearson Correlation Coefficient between centralization level and Effectiveness of Strategies

\begin{tabular}{cccccc}
\hline Variable & abundance & average & $\begin{array}{c}\text { Standard } \\
\text { deviation }\end{array}$ & $\begin{array}{c}\text { Pearson correlation } \\
\text { coefficient }\end{array}$ & sig \\
\hline Effectiveness of strategies & 117 & 84.63 & 17.817 & & \\
Centralization & 117 & 25.09 & 4.092 & 0.096 & 0.305 \\
\hline
\end{tabular}

\subsection{Prioritizing The Structural Dimensions}

Considering the results of Table 8 and previous explanations, there is a significant relation between formalization and complexity as independent variables, and effectiveness of strategies as the dependent variable in Payam-e-noor University. The effect of formalization on the effectiveness of 
strategies is, regardless of its direction, stronger than that of complexity. Based on the results of Tables 8 , there is no significant relation, with at least $95 \%$ reliability, between centralization and effectiveness of Payam-e-noor University strategies.

\section{Table 8}

Prioritizing the structural dimensions according to their effect on the effectiveness of strategies in Payam-e-noor University

\begin{tabular}{ccccccc}
\hline Rank & Variable & abundance & average & Standard deviation & correlation coefficient & Sig \\
\hline 1 & Formalization & 117 & 16.79 & 3.459 & 0.427 & 0.000 \\
2 & Complexity & 117 & 11.01 & 2.486 & -0.184 & 0.047 \\
3 & Centralization & 117 & 25.09 & 4.092 & 0.096 & 0.305 \\
\hline
\end{tabular}

\section{Conclusion}

Considering the high number of university experts, relatively high number of hierarchical levels in the organizational structure, and high number of academic centers and units widespread around the country, it was expected to see very complex results. The average score of the questionnaires is 11 out of 15, which shows a relatively high complexity. As it was mentioned earlier, with increased complexity, organizational communications, coordination and control become more difficult, and as a result, success levels decrease. The results of this study, significant inverse relation between complexity and strategy effectiveness, confirms this theory.

With increased organizational structure, control and coordination tolls become necessary. One of these tools is organizational procedures and regulations, which enable the top management to control and monitor. As Robbins states, where staff perform accurately described, specialized, repetitive, and limited tasks, their work tend to be standardized and many regulations dominate their behavior. On the other hand, there are several cases of high complexity going along with low levels of formalization. For example, incurrence of too many rules on professional activities of highly educated experts or professionals is not necessary. The results of this study confirm the significant and inverse relation between complexity and strategy effectiveness, confirm the significant and direct relation between formalization and strategy effectiveness. The average score of structural formalization, based on the analytical results if this study, is 16.8 out of 25 , and it can be said that the formalization level in Payam-e-noor University is higher than average.

In other words, relatively high structural complexity accompanies the relatively high formalization. While the number of highly educated experts is high in the university, while based on Robbins theory this should, logically, lead to high structural complexity and Low or lower than average formalization. However, the results do not conform to this theory. This nonconformance can be explained with the fact that low formalization is linked to high complexity of the horizontal type, aka high number of specialists with a long training duration. However, horizontal complexity in Payame-noor University is accompanied by vertical and spatial complexity. Thus, top management needs to establish regulations and procedures for monitoring and control, which in return increases the formalization and facilitates the implementation of strategic decisions. This conforms to the result of significant and direct relation between formalization and strategy effectiveness.

Based on what has been said, while theses 1 and 2 are confirmed, but this university faces several problems in successful strategy implementation and achieving its goals, because of high organizational complexity, even though the formalization level, that has a positive and direct effect, is high. In other words, higher than average formalizations help strategy implementation, while simultaneously, high complexity level hinders strategy implementation with a weaker effect. Considering that the complexity of Payam-e-noor University cannot be reduced, due to the wide spatial domain of university activities and high number of specialists, other approaches should be 
applied to successfully execute the strategies, like Formulating sectional strategies (Formulating strategies for departments and sections) with the cooperation of province managers and their staff.

Based on Robbins, university should be decentralized. Decisions on employment, resignation, gradation, performance, and sectional goals should be taken by faculty. Scientific groups should have enough authority and independence and as a professional organization, educational and research issues should be fully controlled and monitored by faculty and even unit headmasters should not have more than one vote in the decision making process.

Data analysis shows that the centralization average score is 25.1 , out of 40 , meaning a higher than average centralization. This is not consistent with Robbins idea. Based on Robbins theory, centralization level should be low in Payam-e-noor University. In addition, based on management theorists, evidences suggest an inverse relation between centralization and complexity, decentralization is related to high level of complexity. For example, increase in the number of professional experts means an increase in the expertise and capability to take decisions. So when we examine organizational structure, we expect to find high level of complexity with decentralization. But results of this study show a relatively high complexity accompanied by higher than average centralization. It seems that Robbins theory is more based on horizontal complexity. When he concludes "University should have a decentralized structure", this is based on the high number of experts in university and their long duration training. However, when complexity includes high levels of spatial complexity and high levels of vertical complexity, decentralized decision making weakens the top management control and monitoring power. Obviously, this forces the top management to establish more regulations and procedures, which is reflected in this study's results on formalization level. In addition, top management should centralize some of the decision makings, to enforce control and monitoring. This is in conformance with the responsibilities and authorities of university board of trustees and results of centralization level. On the other hand, highly formalized structures can be linked to centralized or decentralized structures, as the can be accompanied by high or low complexity levels.

The other important issue is that considering the subject background explained in section 2, and based on Chandler's theory, with product diversification, organizational structure move toward decentralization, and based on Miles and Snow, centralization level is chosen based on the surrounding environment and the chosen strategy to face it. In other words, regardless of Chandler's method limitations, and based on Chandler, Miles and Snow, it was expected to see a significant relation between centralization level and strategy effectiveness. But the results do not confirm this.

\section{References}

Allison, G. T. (1999). Essence of Decision: Explaining the Cuban Missile Crisis (Boston: Little, Brown, 1971). See also Papp, 382-84.

Amirkabiri, A. (2010). Strategic Management. Tehran: Negah Danesh pub. $4^{\text {th }}$ ed. (In Persian).

Byars, L. L. (1991). Strategic management: formulation and implementation: concepts and cases. HarperCollins Publishers.

Chandler, A. D. (1962). Strategy and Structure. Massachusetts S.: The MIT Press, Cambridge, p. $7-$ 52.

Crittenden, V. L., \& Crittenden, W. F. (2008). Building a capable organization: The eight levers of strategy implementation. Business Horizons, 51(4), 301-309.

David, F. R. (2001). Strategic Management. New Jersey: Prentice-Hall, Inc. 8th ed.

Flood, P. C., Dromgoole, T., Carroll, S. J., \& Gorman, L. (2000). Managing Strategy Implementation: An Organizational Behavior Perspective. Oxford: Blackwell.

Habibpour, K., \& Safari, R. (2009). Comprehensive Manual for Using SPSS In Survey Researches. Tehran, Louyeh pub. 2nd ed., p. 359. 
Higgins, J. M. (1983). Organizational policy and strategic management: Text and cases. Dryden Press.

Hoskisson, R. E., Hitt, M. A., \& Ireland, R. D. (2008). Competing for advantage. South-Western Pub. Hunger, D. J., \& Wheelen, T. L. (2008). Concepts on Strategic Management and Business Policy.

Jauch, L. R., \& Glueck, W. F. (1988). Business policy and strategic management (5th ed.). Singapore: McGraw-Hill.

Jooste, C., \& Fourie, B. (2009). The role of strategic leadership in effective strategy implementation: Perceptions of South African strategic leaders. Southern African Business Review, 13(3).

Kaplan, R. S., \& Norton, D. P. (2001). The strategy-focused organization: How balanced scorecard companies thrive in the new business environment. Harvard Business Press.

Miles, R. E., Snow, C. C., Meyer, A. D., \& Coleman Jr, H. J. (1978). Organizational strategy, structure, and process. Academy of management review, 546-562.

Miner, J. B. (1982). Theories of organizational structure and process. Chicago: Dryden Press.

Mintzberg, H. (1979). The structuring of organizations: A synthesis of the research. University of Illinois at Urbana-Champaign's Academy for Entrepreneurial Leadership Historical Research Reference in Entrepreneurship.

Mintzberg, H. A., \& Lampel, B. J.(1998) Strategy safari: a guided tour through the wilds of strategic management.

Noble, C. H. (1999). Building the strategy implementation network. Business Horizons, 42(6), 19-28.

Okumus, F. (2001). Towards a strategy implementation framework.International Journal of Contemporary Hospitality Management, 13(7), 327-338.

Okumus, F. (2003). A framework to implement strategies in organizations.Management Decision, 41(9), 871-882.

Rezaeian, Ali. (2003). Principles of Organization and Management, Tehran, Samt pub. 4th ed. pp. 250-294.

Robbins, S. P. (1990). Organization Theory: Structures, Designs, And Applications, 3/e. Pearson Education India.

Sarmad, Z., Bazargan, A., \& Hejazi, E. (2006). Research Methods for Behavioral Sciences, Tehran: Agah pub. 12th ed. Pp. 90-187.

Sekaran, U. M. (1984). Research methods for managers: A skill building approach. JOHN WILEY \& SONS, INC., 605 THIRD AVE., NEW YORK, NY 10158, USA, 1984, 352.

Simon, H. A. (1976). Administrative behavior (Vol. 3). New York: Free Press.

Thompson, A. A., Strickland, A. J., \& Gamble, J. E. (1998). Strategic management: Concepts and cases. Irwin/McGraw-Hill.

Yang, L., Sun, G. H., \& Eppler, M. (2009). Making strategy work: A literature review on the factors influencing strategy implementation. Handbook of research on Strategy Process, 165-181. 